\title{
Clinico-pathological features of oropharyngeal squamous cell carcinomas in Malaysia with reference to HPV infection
}

Lee Fah Yap ${ }^{1,2}$, Sook Ling Lai ${ }^{1}$, Anthony Rhodes ${ }^{3}$, Hans Prakash Sathasivam ${ }^{4,5}$, Maizaton Atmadini Abdullah ${ }^{6}$, Kin-Choo Pua ${ }^{7}$, Pathmanathan Rajadurai ${ }^{8}$, Phaik-Leng Cheah ${ }^{9}$, Selvam Thavaraj ${ }^{10}$, Max Robinson ${ }^{4}$ and lan C. Paterson ${ }^{1,2^{*}}$ (D)

\begin{abstract}
Background: The incidence of oropharyngeal squamous cell carcinoma (OPSCC) has been rising in Western countries and this has been attributed to human papillomavirus (HPV) infection. p16 expression is a marker for HPV infection and p16 positive OPSCC is now recognized as a separate disease entity. There are only limited data available regarding HPVrelated OPSCC in Asian countries and no data from Malaysia.
\end{abstract}

Methods: We identified 60 Malaysian patients with OPSCC over a 12-year period (2004-2015) from four different hospitals in two major cities, Kuala Lumpur and Penang. The detection of HPV was carried out using p16 immunohistochemistry and high risk HPV DNA in situ hybridisation.

Results: Overall, 15 (25\%) tumours were p16 positive by immunohistochemistry, 10 of which were also positive for high risk HPV DNA by in situ hybridisation. By comparison, a matched cohort of UK patients had a p16 positive rate of 49\%. However, between 2009 and 2015, where cases were available from all four hospitals, 13 of 37 (35\%) cases were 16 positive. In our Malaysian cohort, 53\% of patients were of Chinese ethnicity and 80\% of the p16 positive cases were found in these patients; no Indian patients had p16 positive disease, despite representing 35\% of the total cohort.

Conclusion: The proportion of OPSCCS associated with HPV in Malaysia appears to be lower than in European and American cohorts and could possibly be more prevalent amongst Malaysians of Chinese ethnicity. Further, our data suggests that the burden of HPV-related OPSCC could be increasing in Malaysia. Larger cross-sectional studies of Malaysian patients are required to determine the public health implications of these preliminary findings.

Keywords: Oropharyngeal, Squamous cell carcinoma, p16, Human papillomavirus, Malaysia

\section{Background}

The profile of head and neck squamous cell carcinoma (SCC) has changed over the past few decades with increased rates of oropharyngeal SCC (OPSCC) having been documented in Europe and the USA [1]. Although risk factors such as tobacco and alcohol consumption are still important for the development of OPSCC, it has become apparent that oncogenic human papillomavirus (HPV) is also an important aetiological agent [2]. HPV is

\footnotetext{
* Correspondence: ipaterson@um.edu.my

${ }^{1}$ Faculty of Dentistry, University of Malaya, Kuala Lumpur, Malaysia

${ }^{2}$ Oral Cancer Research and Coordinating Centre, Faculty of Dentistry,

University of Malaya, Kuala Lumpur, Malaysia

Full list of author information is available at the end of the article
}

thought to account for the relatively recent increase in OPSCC, with data from Sweden and the USA indicating that $70-80 \%$ of OPSCC are HPV positive [3, 4]. Patients with HPV positive tumours are typically non-smokers and have a low consumption of alcohol. Sexual behaviour, such as early age of sexual debut and increasing numbers of sex partners appears to correlate with HPV-related OPSCC [5, 6]. Furthermore, HPV-related OPSCC patients have better survival rates than those with HPV negative tumours [6-12].

p16 immunohistochemistry is used clinically as a surrogate marker for oncogenic HPV infection in OPSCCs and in 2017 UICC and AJCC TNM8 classification assigned p16 positive OPSCC a separate staging system

(c) The Author(s). 2018 Open Access This article is distributed under the terms of the Creative Commons Attribution 4.0 International License (http://creativecommons.org/licenses/by/4.0/), which permits unrestricted use, distribution, and 
[13]. In developed countries, routine testing for p16 is now recommended for all patients with OPSCC as well as those with metastatic SCC of unknown primary in the head and neck region $[14,15]$.

At this point in time, there is a lack of accurate epidemiological and clinico-pathological data on the burden of HPV-related OPSCC in Malaysia, as reported by the HPV Information Centre [16]. Two previous studies on HPV-related HNSCCs in Malaysian patients were performed on mostly oral SCC specimens and as such are not representative of the burden of HPV-related OPSCC in Malaysia $[17,18]$. Therefore, the aim of this study was to measure the proportion of Malaysian patients with p16 positive OPSCC and to examine the clinico-pathological features.

\section{Methods}

\section{Patients and specimens}

To ensure that the cohort was representative of the Malaysian population and to limit bias, cases were obtained from four different hospitals in two major cities. Cases were identified by searching pathology databases for SCCs coded as oropharynx, tonsil and soft palate. The patients were identified over a 12-year period (2004-2015). Formalin-fixed paraffin-embedded (FFPE) tissue blocks were obtained from the relevant pathology tissue archives and clinico-pathological information were obtained from clinical databases and review of medical records. All patient information was anonymised. This study had ethical approval from the relevant institutional medical research and ethics boards (Reference Numbers: NMRR-12-13,577; UMMC 20164-2341; SDMC 201211.3).

A matched UK cohort of patients was identified from an existing database at Newcastle-upon-Tyne Hospitals NHS Foundation Trust. Cases were matched by year of diagnosis, age at diagnosis ( \pm 10 years) and sex. Results for p16 immunohistochemistry staining were obtained from patient records. The study had favourable ethical opinion from the National Research Ethics Service Committee North East, Sunderland (REC reference: 11/NE/0118).

\section{HPV testing}

\section{p16 immunohistochemistry}

p16 immunohistochemistry (IHC) was performed using a proprietary kit (CINtec Histology, Roche mtm laboratories AG, Germany) on a Ventana Benchmark Autostainer (Ventana Medical Systems Inc., USA). Normal tonsil was used as a negative control and OPSCC with high p16 expression was used as a positive control. p16 staining was assessed as positive when there was strong and diffuse nuclear and cytoplasmic staining present in greater than $70 \%$ of the malignant cells $[19,20]$.

\section{High risk HPV DNA in situ hybridisation}

HR- HPV DNA in-situ hybridisation (HR-HPV ISH) was carried out using proprietary reagents (Inform HPV III Family 16 Probe (B), Ventana Medical Systems Inc., USA) on a Benchmark Autostainer (Ventana Medical Systems Inc., USA). The Inform HPV III Family 16 Probe (B) detects high risk genotypes HPV-16, - 18, $31,-33,-35,-39,-45,-51,-52,-56,-58$ and -66 . Three control samples were used: FFPE CaSki cells (HPV-16 positive; $200-400$ copies per cell), HeLa cells (HPV-18 positive; 10-50 copies per cell) and C-33A (HPV negative; Ventana Medical Systems Inc., USA). The HR- HPV ISH test was scored as positive if there was any blue reaction product that co-localised with the malignant cells [21].

\section{Statistical analysis}

Statistical analysis was performed using SPSS for Windows (version 21.0; SPSS Inc., USA). p16 positive and negative cases and patient characteristics were compared using independent t tests and Pearson's Chi Square test. Results were considered significant at the $5 \%$ level $(p<0.05)$.

\section{Results}

\section{HPV status of OPSCCs}

We tested OPSCCs from 60 patients identified from four hospitals. 15 (25\%) cases showed p16 expression, but only 10 of the p16 positive tumours (67\%) showed evidence of high risk HPV DNA by in situ hybridisation (Table 1; Fig. 1). To make a more representative comparison, we identified samples collected from all four hospitals within the same period of time. A total of 37 samples were collected between 2009 and 2015 and 35\% (13 of 37) of these cases were p16 positive.

\section{Clinico-pathological profile of patients}

Complete demographic data were available for $54 \mathrm{pa}$ tients; the age and sex for six of the patients were not available. The clinico-pathological profiles of the patients are shown in Table 2. The mean age of patients was 65.44 years $( \pm 12.16)$ at diagnosis and ranged from 36 to 93 years-old. There was no statistically significant difference in age between patients who had p16 negative and p16 positive OPSCC $(p=0.214)$. However, the two youngest (36 and 41 years of age) patients in the cohort had p16 positive disease. The overall male to female ratio was 2.4:1 and the ratio was similar in p16 negative cases (2.7:1), however, the ratio was lower in p16 positive cases (1.6:1). Most patients in the cohort were of Chinese ethnicity $(53.3 \%)$ followed by Indians (35.0\%). All the Indian patients had p16 negative disease, whilst $80 \%$ of the HPV positive cases were Chinese; this finding was statistically significant $(p=0.004)$. Overall, most of the 
Table 1 Demographics of Malaysian patients with p16 positive

\begin{tabular}{|c|c|c|c|c|c|c|}
\hline Case & Year of diagnosis & Age & Sex & Ethnicity & $\begin{array}{l}\text { p16 } \\
\text { IHC }\end{array}$ & HR-HPV ISH \\
\hline 1 & 2005 & NK & NK & Malay & + & - \\
\hline 2 & 2006 & 88 & $\mathrm{~F}$ & Chinese & + & + \\
\hline 3 & 2009 & 41 & $\mathrm{~F}$ & Chinese & + & - \\
\hline 4 & 2010 & 64 & $\mathrm{~F}$ & Chinese & + & + \\
\hline 5 & 2012 & 56 & M & Chinese & + & - \\
\hline 6 & 2012 & 56 & M & Chinese & + & + \\
\hline 7 & 2012 & 67 & $\mathrm{~F}$ & Chinese & + & + \\
\hline 8 & 2013 & NK & NK & Chinese & + & + \\
\hline 9 & 2013 & 74 & M & Malay & + & + \\
\hline 10 & 2013 & 36 & M & Malay & + & + \\
\hline 11 & 2013 & 53 & M & Chinese & + & + \\
\hline 12 & 2013 & 70 & M & Chinese & + & - \\
\hline 13 & 2014 & 72 & M & Chinese & + & - \\
\hline 14 & 2014 & 72 & $\mathrm{~F}$ & Chinese & + & + \\
\hline 15 & 2015 & 54 & M & Chinese & + & + \\
\hline
\end{tabular}

OPSCC were classified as moderately differentiated SCC $(40 \%)$ and this was similar for p16 negative cases (47\%). By contrast, the majority of p16 positive cases $(60 \%)$ were poorly differentiated SCC, which was statistically significant $(p=0.016)$.

\section{Comparison with a matched UK cohort}

A UK cohort of patients with OPSCC was used as a comparator. The Malaysian patients were matched with UK patients by year of diagnosis, age at diagnosis ( \pm 10 years) and sex. Fifty-one patients could be matched between the cohorts; six Malaysian patients had incomplete demographic data and three had data that could not be matched with a UK counterpart. The matched UK patients had a p16 positive rate of $49 \%$, which was double that of the Malaysian patients (24\%).

\section{Discussion}

In previous years, SCCs of the oral cavity and oropharynx were often grouped together and thought of as being a single disease entity [22]. However, this has changed in recent years due to the recognition of HPV as a major aetiopathogenic agent in a subset of OPSCC. HPV positive OPSCC is now recognised as a clinico-pathologically unique form of HNSCC with distinct demographic, clinical and morphological features, as well as being associated with improved clinical outcomes [7, 23-26]. These findings have prompted the changes to oropharyngeal tumours in the 2017 edition of the WHO Classification of Head and Neck Tumours. The new edition has divided tumours of the oral cavity and oropharynx into different chapters and has also sub-classified OPSCC according to HPV status [27]. Furthermore, the UICC and AJCC have recently recommended new clinical and pathological
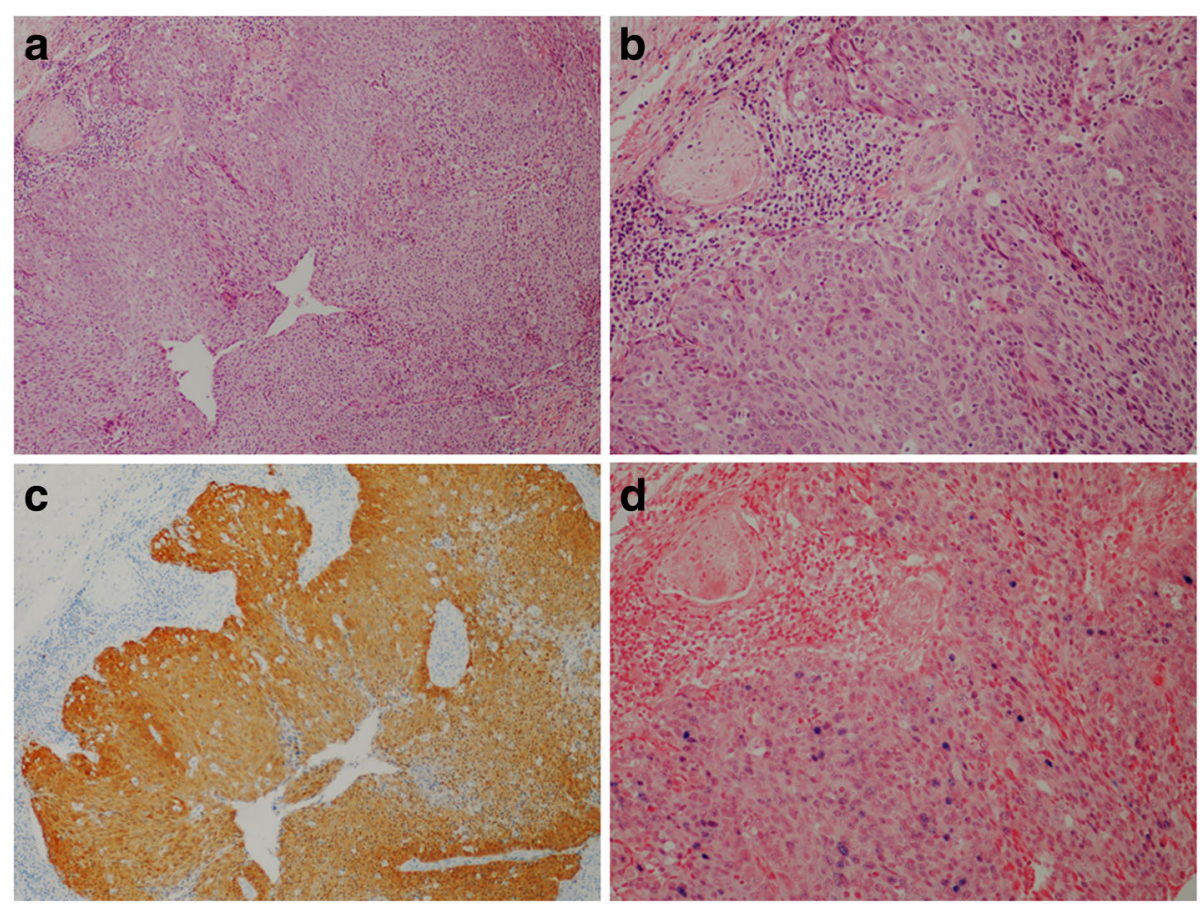

Fig. 1 HPV-related oropharyngeal squamous cell carcinoma (a \& b; H\&E stain) showing high levels of p16 expression by immunohistochemistry (c) and evidence of high risk HPV DNA by in situ hybridisation (d) 
Table 2 Clinico-pathological characteristics of Malaysian patients with OPSCC

\begin{tabular}{lllll}
\hline \multicolumn{1}{c}{$\begin{array}{c}\text { All patients } \\
(n=60 ; 100 \%)\end{array}$} & $\begin{array}{l}\text { p16 negative } \\
(n=45 ; 75 \%)\end{array}$ & $\begin{array}{l}\text { p16 positive } \\
(n=15 ; 25 \%)\end{array}$ & -value \\
\hline $\begin{array}{l}\text { Age at diagnosis (years; } n=54) \\
\text { Mean ( } \pm \text { SD) }\end{array}$ & $65.44( \pm 12.16)$ & $66.61( \pm 11.36)$ & $61.77( \pm 14.28)$ & ${ }^{\mathrm{a}} 0.214$ \\
Sex $(n=54)$ & & & & \\
Male & $38(70.4 \%)$ & $30(73.2 \%)$ & $8(61.5 \%)$ & ${ }^{\mathrm{b}} 0.493$ \\
Female & $16(29.6 \%)$ & $11(26.8 \%)$ & $5(38.5 \%)$ & \\
Ethnicity $(n=60)$ & & & \\
Malay & $7(11.7 \%)$ & $4(8.9 \%)$ & $3(20 \%)$ & ${ }^{\mathrm{b}} 0.004$ \\
Chinese & $32(53.3 \%)$ & $20(44.4 \%)$ & $12(80 \%)$ & \\
Indian & $21(35.0 \%)$ & $21(46.7 \%)$ & $0(0 \%)$ & \\
Broder's grade $(n=60)$ & & & \\
WD & $16(26.7 \%)$ & $13(28.9 \%)$ & $3(20.0 \%)$ & ${ }^{\mathrm{b}} 0.016$ \\
MD & $24(40.0 \%)$ & $21(46.7 \%)$ & $3(20.0 \%)$ & \\
PD & $17(28.3 \%)$ & $8(17.8 \%)$ & $9(60.0 \%)$ & \\
Others & $3(5.0 \%)$ & $3(6.7 \%)$ & $0(0 \%)$ & \\
\hline
\end{tabular}

Independent sample's t-test

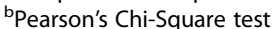

WD Well differentiated, $M D$ Moderately differentiated, $P D$ Poorly differentiated

staging systems for $\mathrm{p} 16$ positive OPSCC, which reflects the improved prognosis of the disease $[13,28]$.

The prevalence of $\mathrm{p} 16$ positive OPSCC in the Malaysian cohort was half that of a matched UK cohort $(25 \%$ vs. $49 \%$ ). The matched UK cohort was representative of a larger $(n=1529)$ multicentre prevalence study carried out in the UK demonstrating that OPSCC had a p16 positive rate of $54 \%$ [29]. Higher rates have also been reported elsewhere in Europe and America (35\% vs 80\%) [1]. A recent meta-analysis looking at the burden of HPV related head and neck cancers in the Asia Pacific region reported an overall prevalence of $40.53 \%$ for oropharyngeal cancers [30]. However, there were considerable differences in the rates between regions and countries; the region with the highest prevalence was Oceania (49.32\%) and the country with the lowest prevalence was China (9.50\%) [30]. Our findings taken for cases diagnosed between 2009 and 2015 (35\%) are comparable to the reported rates in East and South Asian regions (25.8 and $38.7 \%$ respectively) and Singapore (42\%) [31]. In the present study, $80 \%$ of the p16 positive cases were from patients of Chinese ethnicity, whilst all the Indian patients had p16 negative OPSCC. This finding could be particularly relevant because according to the 2010 Population and Housing Census of Malaysia, the Chinese account for only $24.6 \%$ of the total population [32]. Although this potentially alarming finding needs to be confirmed in a larger cohort, further research specifically into risk factors that predispose to
HPV infection in the oropharynx are warranted in different populations.

Most epidemiological and clinical studies have indicated that patients with HPV positive OPSCC are relatively younger than patients with HPV negative disease [6, 30, 33-35], although our findings do concur with those studies with the mean age of HPV positive patients being slightly lower than the mean age of HPV negative patients, the finding was not statistically significant. According to the recent meta-analysis by Shaikh et al. [30], the prevalence of HPV associated head and neck cancer is higher amongst males, however the studies involved in the meta-analysis involved small study samples as well as unequal gender distributions [30]. The findings from our study are also similar with the findings of the meta-analysis with a slight male predilection.

The recent WHO 2017 edition has discouraged histologic grading of HPV positive OPSCC as there is insufficient evidence to correlate histopathological grading with clinical behaviour and outcomes [27]. All the cases in our study were diagnosed well before the release of the new WHO guideline and were based on previous guidelines that grouped oropharyngeal SCCs with oral cavity SCCs. The majority of HPV positive cases were graded as being poorly differentiated SCCs (70\%). This "high grade" histopathologic category was probably based on the non-keratinized, immature and basaloid appearance of the tumour cells. However, such grading may not be accurate as HPV positive OPSCCs mostly arise from the epithelial lining of the tonsillar crypts and therefore retain the non-keratinizing and basaloid appearance of this epithelium.

The disparity between $\mathrm{p} 16$ positive rates $(25 \%)$ and the detection of HR-HPV DNA (17\%) is a consequence of the low sensitivity of HR-HPV DNA in situ hybridisation, which has been reported previously [36]. The relatively high rate of p16 positive, high risk HPV DNA ISH negative cases (5 of 15) is likely to reflect pre-analytical variables related to tissue fixation, processing and storage conditions. The HPV tests were conducted in an ISO15189:2012 accredited UK pathology laboratory, where such cases represent around 10\% of OPSCCs tested [21]. The use of polymerase chain reaction and RNA-based in situ hybridisation has been shown to increase the detection rates and mitigate against false negative results [37].

\section{Conclusion}

The results from this study suggest that the occurrence of HPV-related OPSCC in Malaysia may not be as high as those reported in developed nations such as the UK and the USA, but the proportion of OPSCCs that are HPV positive appears to be increasing, particularly in patients of Chinese ethnicity. Further studies will be 
required to determine how these observations might impact upon Malaysian communities and the national healthcare system in the future.

\section{Abbreviations}

HPV: Human papillomavirus; ISH: In-situ hybridisation; OPSCC: Oropharyngeal squamous cell carcinoma; SCC: Squamous cell carcinoma

\section{Acknowledgments}

The authors would like thank the Director General of Health of Malaysia for his permission to publish this article.

\section{Funding}

This study was supported in part by a High Impact Research Grant (UM.C) 625/1/HIR/MOHE/DENT/22) from the University of Malaya awarded to ICP and LFY. The funding body had no role in the design of the study or the analysis of the data.

\section{Availability of data and materials}

All data generated or analysed during this study are included in this published in this article. The datasets used and/or analyzed during the current study are available from the corresponding author on reasonable request.

\section{Authors' contributions}

LFY, MR and ICP conceived the study. MAA, KCP, PR and PLC identified suitable cases, provided samples and clinical details. MR and ST performed and analysed the immunohistochemistry and in-situ hybridisation. SLL participated in study design and undertook data collection. HPS undertook data collection and performed statistical analysis. LFY, HPS, MR and ICP drafted the manuscript. All authors approved the final manuscript.

\section{Ethics approval and consent to participate}

This study had ethical approval from the relevant institutional medical research and ethics boards (Reference Numbers: NMRR-12-13,577; UMMC 20164-2341; SDMC 201211.3; 11/NE/0118).

\section{Competing interests}

The authors declare that they have no competing interests.

\section{Publisher's Note}

Springer Nature remains neutral with regard to jurisdictional claims in published maps and institutional affiliations.

\section{Author details \\ ${ }^{1}$ Faculty of Dentistry, University of Malaya, Kuala Lumpur, Malaysia. ${ }^{2}$ Oral Cancer Research and Coordinating Centre, Faculty of Dentistry, University of Malaya, Kuala Lumpur, Malaysia. 'School of Medicine, Taylor's University, Subang Jaya, Selangor, Malaysia. ${ }^{4}$ Centre for Oral Health Research, Newcastle University, Newcastle-upon-Tyne, UK. ${ }^{5}$ Ministry of Health, Kuala Lumpur, Malaysia. ${ }^{6}$ Faculty of Medicine and Health Sciences, University Putra Malaysia, Serdang, Malaysia. ${ }^{7}$ Penang General Hospital, Penang, Malaysia. ${ }^{8}$ Subang Jaya Medical Centre, Subang Jaya, Selangor, Malaysia. ${ }^{9}$ Faculty of Medicine, University of Malaya, Kuala Lumpur, Malaysia. ${ }^{10}$ Head and Neck Pathology, Dental Institute, King's College London, London, UK.}

Received: 25 April 2018 Accepted: 4 June 2018

Published online: 11 June 2018

\section{References}

1. Mehanna H, Beech T, Nicholson T, El-Hariry I, McConkey C, Paleri V, et al. Prevalence of human papillomavirus in oropharyngeal and nonoropharyngeal head and neck cancer-systematic review and metaanalysis of trends by time and region. Head Neck. 2013;35:747-55.

2. Leemans CR, Braakhuis BJM, Brakenhoff RH. The molecular biology of head and neck cancer. Nat Rev Cancer Nature Publishing Group. 2011;11:9-22.

3. Nasman A, Attner P, Hammarstedt L, Du J, Eriksson M, Giraud G, et al. Incidence of human papillomavirus (HPV) positive tonsillar carcinoma in Stockholm, Sweden: an epidemic of viral-induced carcinoma? Int J Cancer. 2009;125:362-6.
4. Chaturvedi AK, Engels EA, Pfeiffer RM, Hernandez BY, Xiao W, Kim E, et al. Human papillomavirus and rising oropharyngeal cancer incidence in the United States. J Clin Oncol. 2011;29:4294-301.

5. D'Souza G, Kreimer AR, Viscidi R, Pawlita M, Fakhry C, KOch WM, et al. Casecontrol study of human papillomavirus and Oropharyngeal Cancer. N Engl J Med. 2007:356:1944-56.

6. Gillison ML, D'Souza G, Westra W, Sugar E, Xiao W, Begum S, et al. Distinct risk factor profiles for human papillomavirus type 16-positive and human papillomavirus type 16-negative head and neck cancers. J Natl Cancer Inst. 2008;100:407-20.

7. Ang KK, Harris J, Wheeler R, Weber R, Rosenthal DI, Nguyen-Tan PF, et al. Human papillomavirus and survival of patients with oropharyngeal cancer. N Engl J Med. 2010;363:24-35.

8. Chaturvedi AK, Engels EA, Anderson WF, Gillison ML. Incidence trends for human papillomavirus-related and -unrelated oral squamous cell carcinomas in the United States. J Clin Oncol. 2008;26:612-9.

9. Marur S, D'Souza G, Westra WH, Forastiere AA. HPV-associated head and neck cancer: a virus-related cancer epidemic. Lancet Oncol Elsevier Ltd. 2010;11:781-9.

10. Mellin H, Friesland S, Lewensohn R, Dalianis T, Munck-Wikland E. Human papillomavirus (HPV) DNA in tonsillar cancer: clinical correlates, risk of relapse, and survival. Int J Cancer. 2000;89:300-4.

11. O'Rorke MA, Ellison MV, Murray $\sqcup$, Moran M, James J, Anderson LA. Human papillomavirus related head and neck cancer survival: a systematic review and meta-analysis. Oral Oncol. 2012;48:1191-201.

12. Sturgis EM, Cinciripini PM. Trends in head and neck cancer incidence in relation to smoking prevalence: an emerging epidemic of human papillomavirusassociated cancers? Cancer. 2007;110:1429-35.

13. Huang SH, O'Sullivan B. Overview of the 8th edition TNM classification for head and neck Cancer. Curr treat Options Oncol. 2017:18:40.

14. Paleri V, Roland N. Head and neck Cancer: UK multidisciplinary management guidelines. 5th edition. J Laryngol Otol. 5th ed. London: British Association of Otorhinolaryngology, head and neck Surgery; 2016;130:S3-224.

15. Helliwell T, Woolgar J. Dataset for histopathology reporting of mucosal malignancies of the oral cavity. In: Stand. Datasets report. Cancers. London: the Royal College of Pathologists; 2013.

16. Bruni L, Barrionuevo-Rosas L, Albero G, Serrano B, Mena M, Gómez D, et al. Human papillomavirus and related diseases in Malaysia. Summary report ICO Inf. Cent. HPV Cancer (HPV Inf. Centre). 2017.

17. Saini R, Tang T-H, Zain RB, Cheong SC, Musa Kl, Saini D, et al. Significant association of high-risk human papillomavirus (HPV) but not of p53 polymorphisms with oral squamous cell carcinomas in Malaysia. J Cancer Res Clin Oncol Germany. 2011;137:311-20.

18. Lim KP, Hamid S, Lau S-H, Teo S-H, Cheong SC. HPV infection and the alterations of the pRB pathway in oral carcinogenesis. Oncol Rep Greece. 2007;17:1321-6.

19. Singhi AD, Westra WH. Comparison of human papillomavirus in situ hybridization and p16 immunohistochemistry in the detection of human papillomavirus-associated head and neck cancer based on a prospective clinical experience. Cancer. 2010;116:2166-73.

20. Jordan RC, Lingen MW, Perez-Ordonez B, He X, Pickard R, Koluder M, et al. Validation of methods for Oropharyngeal Cancer HPV status determination in US cooperative group trials. Am J Surg Pathol. 2012;36:945-54.

21. Thavaraj S, Stokes A, Guerra E, Bible J, Halligan E, Long A, et al. Evaluation of human papillomavirus testing for squamous cell carcinoma of the tonsil in clinical practice. J Clin Pathol. 2011;64:308-12.

22. Barnes L, Eveson JW, Reichart P, Sidransky D. Pathology and genetics of head and neck Tumours. First edit. Lyon. France: World Health Organization, IARC; 2005.

23. Westra $\mathbf{W H}$. The changing face of head and neck Cancer in the 21st century: the impact of HPV on the epidemiology and pathology of oral Cancer. Head Neck Pathol New York: Humana Press Inc. 2009:3:78-81.

24. Gondim DD, Haynes W, Wang X, Chernock RD, El-Mofty SK, Lewis JSJ. Histologic typing in Oropharyngeal squamous cell carcinoma: a 4-year prospective practice study with p16 and high-risk HPV mRNA testing correlation. Am J Surg Pathol United States. 2016;40:1117-24.

25. Gillison ML, Chaturvedi AK, Anderson WF, Fakhry C. Epidemiology of human papillomavirus-positive head and neck squamous cell carcinoma. J Clin Oncol United States. 2015:33:3235-42.

26. Hayes DN, Van Waes C, Seiwert TY. Genetic landscape of human papillomavirus-associated head and neck Cancer and comparison to tobacco-related tumors. J Clin Oncol United States. 2015;33:3227-34. 
27. El-Naggar A, Chan J, Grandis J, Takata T, Slootweg P, editors. WHO classification of head and neck Tumours. 4th ed. WHO/IARC classification of Tumours; 2017.

28. Brierley J, Gospodarowicz M, Wittekind C. UICC International Union against Cancer TNM classification of malignant Tumours 8th edition. 8th Editio. Wiley-Blackwell; 2017.

29. Schache AG, Powell NG, Cuschieri KS, Robinson M, Leary S, Mehanna H, et al. HPV-related oropharynx cancer in the United Kingdom: an evolution in the understanding of disease etiology. Cancer Res United States. 2016;76: 6598-606.

30. Shaikh MH, McMillan NA, Johnson NW. HPV-associated head and neck cancers in the Asia Pacific: a critical literature review \& meta-analysis. Cancer Epidemiol. 2015;39:923-38.

31. Tan LSY, Fredrik P, Ker L, Yu FG, Wang DY, Goh BC, et al. High-risk HPV genotypes and P16INK4a expression in a cohort of head and neck squamous cell carcinoma patients in Singapore. Oncotarget. 2016;7:86730-9.

32. 2010 Population and Housing Census of Malaysia. Malaysian department of Statistics; 2011.

33. Ryerson AB, Peters ES, Coughlin SS, Chen WW, Gillison ML, Reichman ME, et al. Burden of potentially human papillomavirus-associated cancers of the oropharynx and oral cavity in the US, 1998-2003. Cancer. 2008;113:2901-9.

34. Llewellyn CD, Johnson NW, Warnakulasuriya KA. Risk factors for squamous cell carcinoma of the oral cavity in young people-a comprehensive literature review. Oral Oncol England. 2001;37:401-18.

35. Gillison ML. Human papillomavirus and prognosis of Oropharyngeal squamous cell carcinoma: implications for clinical research in head and neck cancers. J Clin Oncol American Society of Clinical Oncology. 2006;24: 5623-5.

36. Schache AG, Liloglou T, Risk JM, Jones TM, Ma X-J, Wang H, et al. Validation of a novel diagnostic standard in HPV-positive oropharyngeal squamous cell carcinoma. Br J Cancer. 2013;108:1332-9.

37. Robinson M. HPV testing of head and neck Cancer in clinical practice. Recent Results Cancer Res. 2017:206:101-11.

Ready to submit your research? Choose BMC and benefit from:

- fast, convenient online submission

- thorough peer review by experienced researchers in your field

- rapid publication on acceptance

- support for research data, including large and complex data types

- gold Open Access which fosters wider collaboration and increased citations

- maximum visibility for your research: over $100 \mathrm{M}$ website views per year

At BMC, research is always in progress.

Learn more biomedcentral.com/submissions 